action of solvents on paints and varnishes which is in principle fundamental to a proper understanding of the processes involved in the cleaning of pictures and other painted objects. Mr. Rawlins also pointed out that international co-operation in this field has substantially improved, as is exemplified by the increasing influence and activity of the International Council of Museums, the foundation (in 1950) of the International Institute for the Conservation of Historic and Artistic Works, and the recent formation of the New International Centre in Rome.

\section{Fluoridation of Drinking Water}

THE attitude of different countries to fluoridation of water as a means of preventing dental caries has been described by Gerald H. Leatherman and J. A. Ellis, secretary-general and his assistant, respectively, of the Fédération Dentaire Internationale (Health Educ. J., 17, No. 3 ; 1959). The majority of health authorities throughout the world are in favour of fluoridation. They include: Austria, although a few State authorities are undecided; Canada; Great Britain, where the Government has gone on record through the Minister of Health approving fluoridation as a proved method of prevention; Greece; the Eiast German Democratic Republic; Hong Kong; Republic of Ireland; New Zealand, where the Department of Health is campaigning for fluoridation and the Minister of Health has publicly stated his support of fluoridation, although the Government has made no pronouncement either for or against the measure; Norway; Spain; the United States; and Yugoslavia (Republic of Slovenia), where the political, as well as health authorities, are financially supporting fluoridation and propagating it.

In the main, the following countries support fluoridation: Australia, Belgium, Czechoslovakia, Northern Ireland, Italy, Switzerland, and the Union. of South Africa. The following countries are undecided: Denmark, Egypt, Finland, France, Japan, Hungary, Netherlands, Sweden. Opposed to fluoridation are the German Federal Republic, where the health authorities consider the addition of fluorine as dangerous, as fluorine is only harmless in small quantities and there exists a possibility of overdosage as a result of human incompetence; Indonesia, where there are no experts to supervise fuoridation of drinking water and insufficient personnel to practise fluoridation by the topical application method, while only a few big cities have a central water supply ; in Latin America as a whole, there appears to be an absence of initiative on the part of many health authorities, as well as the absence of any movement to stimulate the interest of the municipalities.

\section{Biological Standardization of Drugs}

Tre Research Defence Society, 11 Chandos Street, Cavendish Square, London, W.1, has issued a new pamphlet (No. 10, April 1960, pp. 6) entitled "The Use of Laboratory Animals in the Standardization of Drugs". This explains, by means of straightforward questions and answers, what is meant by standardization of drugs, why it is necessary, why animals must sometimes be used, and what legal control is imposed in tests of this kind.

\section{Exhibit of Invertebrate Evolution}

A STRIKING exhibit entitled "These are Inverte. brates" was opened at the Australian Museum in July 1959. It is $32 \mathrm{ft}$. long and $9 \mathrm{ft}$. high, and shows the main groups of invertebrate animals and their relationships to each other traced by a system of fluoreseent plastic lines and lights which flash in sequence, some eight hundred light globes and ultraviolet light being used. Labels outline the characteristics of each major group and the scientific and popular names of the individual species are shown. A panel informs the visitor how to use the exhibit. Of the total of 215 species displayed, fifty-five are paintings and forty-three are models.

\section{Photoperiodic Response of Some Tropical Plants}

Ir was formerly thought that the small variation in day-length in the tropics could have no appreciable photoperiodic effect on native plants. This has now been refuted by Indian work on rice and other plants. E. Njoku of the Department of Botany, University College, Ibadan, Nigeria, has tested whether certain plants are sensitive to photoperiod when grown at Ibadan (latitude $7^{\circ} 26^{\prime} \mathrm{N}$.) with a day-length varying from $11 \mathrm{hr} .41 \mathrm{~min}$. in December to $12 \mathrm{hr}$. $33 \mathrm{~min}$. in June (Njoku, E., "The Photoperiodic Response of Some Nigerian Plants", J. West African Sci. Assoc., 4, No. 2, 99 ; August 1958). The plants used fell into two main groups, day-neutral and short-day plants. No long-day plants were found. The results suggested that some plants had a critical day-length of less than $12 \mathrm{hr}$. Others flowered in $12 \mathrm{hr}$. but not l4-hr. days, indicating a critical day-length between 12 and $14 \mathrm{hr}$. A critical photoperiod of $12 \mathrm{hr}$. or less would make it possible for day-length to control flowering at the latitude of Ibadan.

Using day-lengths of $11 \frac{1}{2}-12 \frac{1}{2} \mathrm{hr}$, that is, the extremes of day-length at Ibadan, it was shown that late okra (Hibiscus esculentus) and Sphenostylis stenocarpa showed a eritical day-length of less than $12 \frac{1}{2} \mathrm{hr}$., and hence did not flower in the long 'summer' days at this latitude. Early okra and Phaseolus lunatus, on the other hand, flowered in both $11 \frac{1}{2}-\mathrm{hr}$. and $12 \frac{1}{2}-\mathrm{hr}$. days as well as in the natural daylength, but their response was quantitative in nature, the time to flowering being longer in the longer days. In order to test the effect of natural changes in day. length, successive monthly plantings were made in the field throughout the year. The results support the conclusions drawn from the experiments in which day-length was artificially controlled. Hence the photoperiodic response is of practical significance in the latitude of Ibadan. Plants of both groups grown under field conditions showed a marked shortening or lengthening of the vegetative period as the natural photoperiod decreased or increased. A difference of $15 \mathrm{~min}$. may mean flowering or only vegetative growth.

\section{Geology in the U.S.S.R.}

AN announcement of forthcoming publications issued by the Academy of Sciences of the U.S.S.R. lists 120 books on geology to be published in 1960 , excluding periodicals, popular works, and reprints. Much the same order of output appeared last year from the State Publishing House for Geological Literature ("Gosgeoltekhizdat") ; and taking into account the production of other agencies, it seems likely that the geological monographs and text-books published within the U.S.S.R. now number close on five hundred volumes annually. Since much of this literature is little known in the West, a special interest attaches to a paper by Prof. S. I. Tomkeieff on "The Progress of Geology in the U.S.S.R." (Liverpool and Manchester Geological Journal, 2, 474 ; 1960). 